\title{
A DESJUDICIALIZAÇÃO E OS ATOS DE INVENTÁRIO E EUSUCAPIÃO EXTRAJUDICIAIS
}

Rafaela Parpinéli de Oliveira; Fábio Ferreira Morong

Universidade do Oeste Paulista, Presidente Prudente, SP. E-mail: rafaceciliaoliveira@hotmail.com

\section{RESUMO}

O Poder Judiciário responde por uma lentidão na sua prestação jurisdicional, seja pela falta de estrutura ou funcionários em geral. Diante disso, foi consolidada a transferência de alguns atos judiciais como divórcio, inventário e usucapião para Serventias Extrajudiciais. O objetivo deste trabalho é compreender e demonstrar as consequências dessa transferência de competência do Poder Judiciário para a esfera administrativa, explicando a ideia da desjudicialização ou extrajudicialização, e apontando seu resultado, com enfoque especial para os atos de inventário e usucapião. O presente trabalho empregou pesquisas à legislação nacional, sites de órgãos Judiciários e Administrativos, pareceres, votos, portarias, provimentos e opiniões relevantes na matéria objeto de estudo, utilizando o método dedutivo para estruturar as informações obtidas. Conclui-se que as referidas mudanças proporcionaram certos benefícios tanto à população quanto ao próprio Poder Judiciário, contribuindo para a simplificação e desburocratização do sistema.

Palavras-chave: Desjudicialização, Extrajudicialização, Cartórios, Inventário, Usucapião, Serventias Extrajudiciais.

\section{DISCHARGING AND THE ACTS OF EXTRA-JUDICIAL INVENTORY AND USUCATION}

\begin{abstract}
The Judicial Branch responds by slowness in its jurisdictional provision, either by the lack of structure or civil servants in general. In view of this, the transfer of some judicial acts such as divorce, inventory and usucapião for Extrajudicial Services was consolidated. The purpose of this paper is to understand and demonstrate the consequences of this transfer of competence from the Judiciary to the administrative sphere, explaining the idea of the adjudication or extrajudicialization, and pointing out its result, with special focus for the acts of inventory and usucapião. The present work used researches to the national legislation, sites of Judicial and Administrative bodies, opinions, votes, ordinances, provisions and opinions relevant in the subject of study, using the deductive method to structure the information obtained. It is concluded that these changes have provided certain benefits both to the population and to the Judiciary itself, contributing to the simplification and debureaucratization of the system.
\end{abstract}

Keywords: Disqualification, Extrajudicial, Notary Public, Inventory, Usucapião, Extrajudicial Services. 


\section{INTRODUÇÃO}

Atualmente há um número avassalador de processos em trâmite pelo Judiciário pátrio, que atrapalham a rotina dos órgãos julgadores e que seriam facilmente solucionados extrajudicialmente. Diante disto, a desjudicialização mostra-se um caminho obrigatório. Não há outra saída a não ser enxugar o sistema. Foi pensando nisso, que diversas leis foram criadas visando que determinados procedimentos passassem por uma desburocratização.

E qual lugar melhor que os Cartórios para resolverem essa problemática? Os atos notariais e de registro estão presentes durante toda a vida de uma pessoa. Do nascimento ao falecimento faz-se necessário se dirigir a um Oficio de Registro Civil; ou quando se adquire um imóvel; para dar autenticidade á documentos.

Nota-se que são serviços eficientes, dotados de rapidez e econômicos. O que no Judiciário, na maioria das vezes, é o contrário. E é por este motivo que diversos serviços, anteriormente outorgados apenas ao Judiciário foram transpostos para as serventias extrajudiciais.

Foi o que ocorreu com as mudanças introduzidas pela Lei № 11.441 de 2007, a qual permitiu que inventário, partilha, separação e divórcio consensual fossem realizados em Tabelionato de Notas. O mesmo se viu, no campo do Registro Imobiliário, com a Lei no 13.105 de 2015 que alterou a Lei de Registros Públicos acrescendo o artigo 216-A, que permite o reconhecimento extrajudicial de usucapião. O objetivo deste trabalho é compreender e demonstrar as consequências dessa transferência de competência do Poder Judiciário para a esfera administrativa, explicando a ideia da desjudicialização ou extrajudicialização, e apontando seu resultado, com enfoque especial para os atos de inventário e usucapião.

\section{METODOLOGIA}

O método aplicado foi o dedutivo legal, baseado na interpretação da legislação, julgados, portarias, provimentos e em pareceres.

\section{ENTENDENDO O TERMO “DESJUDICIALIZAÇÃO E EXTRAJUDICIALIZAÇÃO”}

Frase das mais corriqueiras em quase todas as discussões, por mais simples que sejam é: eu vou te processar! Essas poucas palavras revelam que a sociedade brasileira está habituada a se envolver em conflitos. (NETO, 2016).

Devido á população estar sempre entrando em conflitos, há um número excessivo de processos em trâmite pelo Judiciário, uma vez que todos estão buscando garantir o seu direito de acesso à Justiça.

É diante disto que constatamos que a desjudicialização é um caminho obrigatório. Mas o que é desjudicialização? Este termo diz respeito à faculdade que as partes possuem para compor seus conflitos fora da esfera judicial, desde que sejam juridicamente capazes e que tenham por objeto direitos disponíveis, na busca de soluções sem a tramitação habitual dos tribunais. (MARQUES, 2014).

Algumas atividades que antes eram outorgadas, com exclusividade, ao Judiciário, foram atribuídas, também, às Serventias Extrajudiciais. Esse deslocamento foi pensado visando trazer agilidade a esses atos e desafogar os nossos Tribunais que estão abarrotados de processos, que muitas vezes, sequer possuem conflito entre as partes. (CHAVES; REZENDE, 2011, p. 316).

A desjudicialização se tornou realidade no Brasil há algum tempo, nos permitindo citar alguns exemplos como: Lei ${ }^{\circ} 8.560 / 92$ que se refere ao reconhecimento de paternidade perante os Cartórios de Registro Civil; Lei $n^{\circ}$ 9.514/97, que trata dos procedimentos de notificação do devedor e leilão extrajudicial nos contratos de alienação fiduciária; Lei $n^{\circ} 10.931 / 2004$, que autoriza a retificação administrativa dos registros imobiliários; Lei no 11.441/2007, que tornou possível a realização de inventário, separação e divórcio consensuais e partilha pelas vias extrajudiciais, ou seja, pelos Tabelionatos de Notas. (MARQUES, 2014). 
Outro progresso recente se deu no campo do Registro Imobiliário. Trata-se da usucapião extrajudicial, que é tratada no artigo 216-A da Lei de Registros Públicos, que foi alterada pelo novo Código de Processo Civil (Lei no 13.105 de 16 de março de 2015). (BRASIL, 2015).

As citadas leis representam uma vantajosa contribuição por parte do legislador para reduzir o conglomerado de processos e viabilizar soluções mais rápidas para as ações pretendidas. A crise da Justiça, representada especialmente por sua inacessibilidade, lentidão e custo, põe imediatamente em destaque o primeiro objetivo pretendido pela desjudicialização: simplificar a distribuição da Justiça e descongestionar os tribunais.

Desjudicalização ou Extrajudicialização é um fenômeno que vem aparecendo no Direito Brasileiro nos últimos anos, que consiste em suma, em elidir do âmbito jurídico atividades que tradicionalmente lhe cabem, deslocando-as para as serventias extrajudiciais. (BRAGA, 2016).

\section{INVENTÁRIO EXTRAJUDICIAL}

No ramo do direito, quando ocorre o óbito de uma pessoa, é realizado o seu inventário e consequente partilha dos eventuais bens entre os indivíduos que se qualificam, ou seja, os herdeiros. (CHAVES; REZENDE, 2011, p. 316).

A respeito do conceito de inventário, Euclides de Oliveira e Sebastião Amorim (2009, p. 299) ensinam que, "o inventário é o procedimento obrigatório para a atribuição legal dos bens aos sucessores do falecido (...)."

Antes do advento da Lei no 11.441 de 04 de janeiro de 2007 este procedimento só se realizava via judicial, sendo bastante burocrático e moroso, além de envolver altos custos judiciais. Bem por isso, o inventário extrajudicial é dotado de benefícios, ou seja, celeridade, praticidade e economia. (COSTA, 2016).

Silvio de Salvo Venosa (apud COSTA, 2016, p. 6), se posiciona sobre o assunto da seguinte forma:

Finalmente, a Lei no 11.441 , de 4 de janeiro de 2007, atendeu nossos ingentes reclamamos [...]. É importante que se libere o Judiciário da atual pletora e feitos de cunho administrativo e o inventário, bem como a partilha, quando todos os interessados são capazes, podem muito bem ser excluídos, sem que se exclua o advogado de sua atuação.

Um requisito exigido para que seja possível realizar o ato nestas Serventias é, a capacidade dos herdeiros (não se confundindo com maioridade). Também é preciso não haver testamento. Sendo descoberto testamento posterior ao inventário extrajudicial, este será anulado, pois deverá ser protegido a última vontade do de cujus. (COSTA, 2016).

O processo de inventário é obrigatório, de acordo com o art. 611 da Lei no 13.105, de 16 de março de 2015, que instituiu o Novo Código de Processo Civil, e seu início deve se dar nos primeiros 60 (sessenta) dias, contados a partir da data do fato ensejador de tal procedimento (morte). Importante destacar que, mesmo que a morte tenha ocorrido antes da entrada em vigor da Lei em estudo, é permissível realizar o inventário extrajudicial nos Tabelionatos de Notas.

Felipe Leonardo Rodrigues e Paulo Roberto Gaiger Ferreira (2014) nos lembram de que para ser realizado o procedimento, extrajudicialmente, é necessário que as partes envolvidas sejam maiores e capazes, que haja consenso entre eles quanto à partilha dos bens e com relação a quem será o inventariante, o falecido não deve ter deixado testamento e a escritura deve contar com a presença de um advogado.

Existe, também, a possibilidade de representação por instrumento público de procuração, com poderes específicos para tal ato, bem como a renúncia à herança, desde que expressa na escritura pública. (TARTUCE, 2017).

Se depois de lavrada a escritura pública, vier à tona outros bens do falecido, pode ser feita a escritura de sobrepartilha, que consiste na realização da partilha de um bem que deveria ter sido incluído no inventário que resta concluído. Devem-se acatar os mesmos requisitos 
observados na lavratura do inventário, com o aumento da apresentação do formal de partilha, da carta de adjudicação ou do processo de inventário. A sobrepartilha pode ser feita por via extrajudicial mesmo que o inventário anterior tenha se dado judicialmente. (COSTA, 2016).

A escolha do cartório para realizar o ato é livre, não dependendo do local de domicílio das partes envolvidas, dos bens ou do óbito. (ATHAYDE, 2014).

Os valores pagos perante as serventias extrajudiciais variam de acordo com o Estado, que possuem diferentes percentuais de cobrança de impostos. Certo está Filho (2015) ao afirmar que, os beneficiados com o procedimento de inventário extrajudicial não são apenas os herdeiros, mas também o Judiciário, posto que se propõe menos ações nas varas de sucessões, caminhando assim para um alivio na máquina Judiciária.

\section{USUCAPIÃO}

A usucapião, em suma, é modalidade de aquisição originária da propriedade, móvel ou imóvel, caracterizada pela posse contínua e pacífica durante determinado tempo. $O$ instituto da usucapião consiste em proporcionar segurança às relações jurídicas ao estabilizar as titularidades aparentes (situação de fato). (NADER, 2016, p. 123).

O procedimento de usucapião extrajudicial é o mais recente no ordenamento jurídico brasileiro, trazido pelo Novo Código de Processo Civil que, sem dúvidas, representa mais um grande avanço ao sistema jurídico pátrio. O procedimento da usucapião extrajudicial apresentouse como uma promessa de desjudicialização e simplificação dos procedimentos, com o intuito de torná-los mais céleres e efetivos. (KUMPEL, 2016).

Já havia previsão da possibilidade da aquisição de direitos sobre imóveis públicos pela via administrativa desde 2001 (Medida Provisória no 2.220/2001), porém a usucapião administrativa somente surgiu com a Lei no 11.977/2009, mais tarde modificada pela Lei $n$ o 12.424/2011, e refletiu um avanço na desjudicialização brasileira. (BRAGA, 2016).

Foi com o advento do Novo CPC que passou a existir uma aplicação integral do procedimento extrajudicial, instituindo o art. 216-A, da Lei no 6.017, de 31 de dezembro de 1973, que constituiu a lei de Registros Públicos. O referido artigo assim prescreve: "Sem prejuízo da via jurisdicional, é admitido o pedido de reconhecimento extrajudicial de usucapião (...)." (BRASIL, 1973).

O art. 1.071, do Novo Código de Processo Civil, modificou a redação do art. 216-A, da Lei de Registros Públicos, o qual passou a ter extensivo espectro de abrangência, se aplicando às diversas modalidades de usucapião. (BRAGA, 2016).

É diante disto que se percebe a importância dos cartórios notariais e de registro, que desempenham papéis importantes na sociedade. No caso da usucapião fica a cargo do Tabelião ou Registrador, presidir e realizar a qualificação jurídica do processo do reconhecimento da aquisição da propriedade imobiliária pela via extrajudicial, nos casos onde não há lide. (BRANDELLI, 2016).

Sobre as obrigações do tabelião ou registrador, dispõe Braga $(2016$, p. 5) em seu artigo de forma clara:

[...] Deverá fazê-lo, com base na natureza jurídica da função registral, promovendo a segurança jurídica, de maneira célere e eficaz, por meio da publicidade, especificidade e continuidade, conferindo eficácia às relações jurídicas noticiadas. Ademais, deverá atender aos princípios que permeiam a função registral imobiliária. Todavia, cabe ao notário colher e autenticar os fatos. A função registral e notarial são funções administrativas, públicas, exercidas por um particular, por sua conta e risco, mediante delegação estatal.

Percebe-se que foi dada uma amplitude de cognição ao Oficial do Registro de Imóveis. É ele que irá reger o procedimento, formando sua conviç̧ão para decidir se anui ou não o pedido de reconhecimento da aquisição pela usucapião extrajudicial. (BRANDELLI, 2016). 
A legitimidade ativa (requerente) pertencia, somente, àquele que tinha a posse ad usucapionem. Porém, esse entendimento foi ampliado se tratando da usucapião extrajudicial, passando a ter legitimidade qualquer pessoa que tenha interesse jurídico justificado, legítimo e comprovado. (NETO, 2016, p. 498).

Já a legitimidade passiva (requerido), no processo extrajudicial, será definida pelo pedido. (NETO, 2016, p. 498).

Conforme disposto no art. 216-A da Lei no 6.015/73, a competência para o procedimento de usucapião pertence ao Cartório de Registro de Imóveis da comarca onde estiver situado o imóvel usucapiendo. (BRANDELLI, 2016, p. 70/71).

O inciso I, do referido artigo, dispõe que para instruir o pedido da usucapião extrajudicial, é imprescindível que o requerimento, que também é um requisito, esteja acompanhado da "ata notarial lavrada pelo tabelião, atestando o tempo de posse do requerente e seus antecessores, conforme o caso e suas circunstancias", a pedido da parte interessada. A ata notarial é um instrumento público, utilizado pelos Tabeliães como meio de obter e certificar atos e fatos. (BRAGA, 2016).

Outro requisito é a planta e o memorial descritivo com a assinatura do profissional habilitado, conforme impõe o inciso II do art. 216-A da Lei de Registros Públicos (BRASIL, 1973).

Além disso, juntamente com o requerimento, deverão ser apresentadas as certidões negativas que apresentem a situação do imóvel em questão. Essas certidões têm o intuito de verificar se há alguma ação que embarace o reconhecimento da ação de usucapião extrajudicial, ou que interrompa o prazo prescricional aquisitivo (BRASIL, 1973).

$O$ inciso IV da Lei em estudo estabelece que o interessado também deverá anexar ao requerimento o "justo título ou quaisquer outros documentos que demonstrem a origem, continuidade, natureza e o tempo de posse, como, por exemplo, pagamento dos impostos". (NETO, 2016, p. 502).

Após cumprido os requisitos e dado andamento ao procedimento administrativo, se a qualificação for sido positiva, o Oficial irá notificar os legitimados passivos, caso esses não tenham anuído espontaneamente no memorial descritivo, para que se manifestem concordando ou não com o pedido. O requerente é quem deverá solicitar a notificação, informando o endereço do notificado e deverá arcar com as despesas da notificação. O Registrador irá notificar o legitimado passivo para concordar, dentro do prazo de 15 dias, a contar do recebimento da notificação. A notificação poderá ser feita pessoalmente, por meio do correio, não sendo admitida notificação por edital, e deverá estar acompanhada de documentos que permitam que o notificado avalie o pedido. (BRAGA, 2016).

Se o notificado estiver em lugar incerto e não sabido, ou esteja simulando sua ocultação para que não seja notificado, o pedido será negado, não podendo ser feito na via extrajudicial. Se após o prazo dos 15 dias o notificado manter-se em silêncio, presumir-se-á que o mesmo não concordou e, sendo assim, o Registrador negará o pedido, conforme disposto no art. 216-A, §2으, da Lei de Registros Públicos. (BRAGA, 2016).

Preenchidos todos os requisitos, o Oficial formará sua convicção, que se positiva irá realizar o ato do registro da aquisição do imóvel. Conforme esclarece Braga (2016), se ao final das diligências, ocorrer de os documentos não estarem em harmonia, o Oficial não acolherá o pedido e irá elaborar nota devolutiva.

\section{CONCLUSÃO}

Através do presente artigo foi possível realizar um breve entendimento a respeito das modificações de competências que vieram com intuito de desafogar a máquina Judiciária, transferindo os casos onde não há lide para as Serventias Extrajudiciais. 
Logo, é possível perceber quão significativas foram às mudanças trazidas pelo Novo CPC e outras leis esparsas, quando simplificaram diversos procedimentos, permitindo que sejam realizados diretamente pela via Administrativa, a qual é, sem dúvidas, mais célere e igualmente eficaz, vez que seus Serventuários são dotados de fé pública.

Conclui-se que as referidas mudanças proporcionaram certos benefícios tanto à população quanto ao próprio Poder Judiciário, contribuindo para a simplificação e desburocratização do sistema.

\section{REFERÊNCIAS}

ATHAYDE, M. Inventário Judicial e Extrajudicial - qual a diferença e qual escolher? Descomplicando o Direito, 2014.2 Disponível em:<https://marceloathayde.wordpress.com/2014/11/26/inventario-judicial-e-extrajudicial-quala-diferenca-e-qual-escolher/>. Acesso em: 21 mai. 2018;

BRAGA, I. J. G. A Desjudicialização do Processo de Usucapião da Propriedade Imobiliária. 2016. 30 f. Trabalho de Conclusão de Curso (Graduação em Direito) - Pontifica Universidade Catolíca, Rio Grande do Sul. Disponível em:<http://conteudo.pucrs.br/wpcontent/uploads/sites/11/2016/09/isadora_braga_2016_1.pdf>. Acesso em: 01 abr. 2018;

BRANDELLI, Leonardo. Usucapião Administrativa. 1ạ. Ed. São Paulo: Saraiva, 2016;

BRASIL. Congresso Nacional. Lei de Registros Públicos. Lei n. 6.015 de 31 de dezembro de 1973. Dispõe sobre os Registros Públicos e dá outras providências. Disponível em:<http://www.planalto.gov.br/ccivil/leis/L6015.htm>. Acesso em: 01 abr. 2018;

BRASIL. Congresso Nacional. Código de Processo Civil. Lei n. 13.105 de 16 de março de 2015. Disponível em:<http://www.planalto.gov.br/ccivil_03/_Ato2015-2018/2015/Lei/L13105.htm>. Acesso em: 01 abr. 2018;

CHAVES, Carlos Fernando Brasil; REZENDE, Afonso Celso F. Tabelionato de Notas e o Notário Perfeito. 6a. Ed. São Paulo: Millennium, 2011;

COSTA, G. S. C. Inventário Extrajudicial.Jusbrasil, 2016. Disponível em:<https://giselelg.jusbrasil.com.br/artigos/307624556/inventario-extrajudicial>. Acesso em: 10 abr. 2018;

KUMPEL, V. F. Onovo CPC e suas Implicações na Atividade Notarial e Registral II: O Instituto da Usucapião Administrativa. Migalhas, abr. 2016.2 Disponível em:<http;//www.migalhas.com.br/Registralhas/98,MI237018,110490+novo+CPC+e+suas+implica ções+na+atividade+notarial+e+registral+II+o>. Acesso em; 30 mar. 2018;

MARQUES, Norma Jeane Fontenelle. Adesjudicialização como forma de acesso à Justiça. In: Âmbito Jurídico, Rio Grande, XVII, n. 123, abr 2014. Disponível em: <http://www.ambitojuridico.com.br/site/index.php?n_link=revista_artigos_leitura\&artigo_id=146 38\&revista_caderno=21>.Acesso em: 15 abr. 2018;

NADER, Paulo, Curso de Direito Civil v.4. 7ạ. Ed. Rio de Janeiro: Forense, 2016; 
NETO, A. D. G. Cartório em Foco. Blog Cartório em Foco, set. 2016. Disponível em:<http://cartorioemfoco.com.br/desjudicializacao/\#more-455>. Acesso em: 08 abr. 2018;

NETO, Arthur Del Guércio, O direito notarial e registral em artigos. 1a. Ed. São Paulo: EDITORA YK, 2016;

OLIVEIRA, Euclides de; AMORIM, Sebastião. Inventários e partilhas. 22ª. Ed. São Paulo: Leud, 2009, p. 299;

TARTUCE, Flávio. Manual de Direito Civil. 6ạ. Ed. São Paulo: Método, 2017. 